\title{
DNA Vaccines: Developing New Strategies against Cancer
}

\author{
Daniela Fioretti, ${ }^{1}$ Sandra Iurescia, ${ }^{1}$ Vito Michele Fazio,,${ }^{2,3}$ and Monica Rinaldi ${ }^{1}$ \\ ${ }^{1}$ Institute of Neurobiology and Molecular Medicine, Department of Medicine, National Research Council (CNR), \\ Via Fosso del Cavaliere 100, 00133 Rome, Italy \\ ${ }^{2}$ Section of Molecular Medicine and Biotechnology, Interdisciplinary Center for Biomedical Research, \\ University Campus Bio-Medico, Via Álvaro del Portillo 21, 00128 Rome, Italy \\ ${ }^{3}$ Unità Operativa Oncologia, Istituto di Ricovero e Cura a Carattere Scientifico Casa Sollievo della Sofferenza, \\ 71013 San Giovanni Rotondo, Foggia, Italy
}

Correspondence should be addressed to Monica Rinaldi, monica.rinaldi@artov.inmm.cnr.it

Received 20 November 2009; Accepted 5 February 2010

Academic Editor: Soldano Ferrone

Copyright ( $\odot 2010$ Daniela Fioretti et al. This is an open access article distributed under the Creative Commons Attribution License, which permits unrestricted use, distribution, and reproduction in any medium, provided the original work is properly cited.

Due to their rapid and widespread development, DNA vaccines have entered into a variety of human clinical trials for vaccines against various diseases including cancer. Evidence that DNA vaccines are well tolerated and have an excellent safety profile proved to be of advantage as many clinical trials combines the first phase with the second, saving both time and money. It is clear from the results obtained in clinical trials that such DNA vaccines require much improvement in antigen expression and delivery methods to make them sufficiently effective in the clinic. Similarly, it is clear that additional strategies are required to activate effective immunity against poorly immunogenic tumor antigens. Engineering vaccine design for manipulating antigen presentation and processing pathways is one of the most important aspects that can be easily handled in the DNA vaccine technology. Several approaches have been investigated including DNA vaccine engineering, co-delivery of immunomodulatory molecules, safe routes of administration, prime-boost regimen and strategies to break the immunosuppressive networks mechanisms adopted by malignant cells to prevent immune cell function. Combined or single strategies to enhance the efficacy and immunogenicity of DNA vaccines are applied in completed and ongoing clinical trials, where the safety and tolerability of the DNA platform are substantiated. In this review on DNA vaccines, salient aspects on this topic going from basic research to the clinic are evaluated. Some representative DNA cancer vaccine studies are also discussed.

\section{Introduction}

Spontaneous tumour regression has followed bacterial, fungal, viral, and protozoal infections. Intratumoral infections may reactivate defensive functions, causing tumour regression.

These phenomena inspired the development of numerous rudimentary cancer immunotherapies, starting with nonspecific immunostimulatory approaches first used by William Coley [1] and leading to the concept of therapeutic vaccination against cancer. The recent identification and characterization of genes coding for tumour antigens (Ag) has enabled the design of antigen-specific cancer vaccines based on plasmid DNA and recombinant viral vectors. Gene therapy can be used to manipulate the immune system to help body's natural defences to recognise and target cancer cells.

In the last few years, it is estimated that in Europe there were almost 3000000 cancer cases diagnosed (excluding non melanoma skin cancers) and more than 1500000 deaths from cancer each year [2]. Standard therapeutic procedures currently in practice, including surgery, radiation, and chemotherapy have not greatly impacted the spread and recurrence of progressive malignancies [3], reducing the ability of the immune system to provoke "spontaneous" regressions. Newer strategies are needed to improve upon the current treatment success rate.

Historically, Wolff and colleagues [4] first demonstrated that long-term gene expression in mouse skeletal muscle could be achieved with direct intramuscular injection of 
plasmid DNA. This and other early studies, demonstrating the feasibility of direct intramuscular gene transfer for DNA vaccination purpose, propelled the first vaccination studies utilizing plasmid DNA in protection scenarios involving influenza [5] and HIV-1 [6]. Cellular and humoral immune responses have been demonstrated after the injection of naked plasmid DNA vaccines into the dermis or muscle tissue of mice $[5,7]$. Such responses have induced protection in preclinical models of infectious disease and malignancies (for review, see Donnelly et al. [8]).

The DNA vaccine is a prime example of a modern genetic vaccine. The use of naked plasmid DNA as vaccine to elicit the immune system against disease provides a variety of practical benefits for large-scale vaccine production that are not as easily manageable with other forms of vaccines including recombinant protein or whole tumor cells $[9,10]$.

The effectiveness to screen for antigens rapidly and to design specific types of expression constructs has made the study of DNA vaccines a valuable field for immunotherapy of cancer.

New technologies including gene-expression profiling has increased the list of candidate tumor antigens. Investigators have focused on targets which are either tumourspecific, including idiotypic antigens of B-cell tumours [11] or tumour-associated antigens [12] that are also expressed by the normal cell of origin [13] and that include the so-called cancer-testis antigens [14].

Examples under intensive investigation are the antigens of melanoma (http://www.cancer.gov/cancertopics/types/ melanoma), prostate cancer (http://www.cancer.gov/cancer topics/types/prostate), and other epithelial cancers (http:// www.cancer.gov/cancertopics/types/skin).

DNA vaccines offer the opportunity to incorporate additional genes encoding molecules aimed at overcoming the weak immunogenicity of tumor antigens and the patients' tolerized immune repertoire.

This paper briefly summarizes findings and key technologies that have contributed to the rapid progress of DNA vaccines (mode of action, design, and optimization of DNA vaccines) as well as the state of the art of some of the more encouraging clinical studies using or against tumor antigens.

\section{Cancer Antigens}

Scientists have identified a large number of cancer-associated antigens, many of which are now being used to perform cancer treatment vaccines both in basic research and in clinical trials. The list of candidate tumor antigens grows daily, largely because of expanding genetic technology including human genome sequencing and gene-expression profiling. Tumor antigens have been classified into two broad categories: tumor-specific shared antigens and tumorspecific unique antigens [15]. Shared antigens or tumorassociated antigens (TAAs) are expressed by more than one type of tumor cells. A number of TAA are also expressed on normal tissues, albeit in different amounts. As reported in the official National Cancer Institute website (NCI, http://www.cancer.gov/), representative examples of such shared antigens are the cancer-testis antigens [14], human epidermal growth factor receptor 2 (HER2)/neu protein (reviewed in [16]), and carcinoembryonic antigen (CEA) [17]. Unique tumor antigens result from mutations induced through physical or chemical carcinogens; they are therefore expressed only by individual tumors. Tumor-specific unique antigens encompass melanocyte/melanoma differentiation antigens, such as tyrosinase [18], MART1 [19] and gp100 [20], prostate-specific antigen (PSA) (reviewed in [21]) and Idiotype (Id) antibodies [11]. Optimally designed cancer vaccines should combine the best tumor antigens with the most effective immunotherapy agents and delivery strategies to achieve positive clinical results. An important dilemma for vaccination against overexpressed tumor-associated antigens is how to induce effective immunity against the chosen target without leading to damaging autoimmunity. The precision offered by DNA vaccines will induce focused immunity against selected antigens, and, as they become more powerful, targets will have to be selected carefully to avoid autoimmunity. Recently, an NCI pilot prioritization study produced a well-vetted, priority-ranked list of cancer antigens [22]. Antigen prioritization involved developing a list of "ideal" cancer antigen criteria/characteristics and assigning relative weights to those criteria using pairwise comparisons. The result of criteria weighting was as follows: (a) therapeutic function, (b) immunogenicity, (c) role of the antigen in oncogenicity, (d) specificity, (e) expression level and percent of antigen-positive cells, (f) stem cell expression, (g) number of patients with antigen-positive cancers, (h) number of antigenic epitopes, and (i) cellular location of antigen expression [22]. Such an effort to prioritize cancer antigens represents the logical next step in attempting to focus translational efforts on cancer vaccine regimens with the highest potential for success.

A biological issue limiting the efficacy of cancer vaccines is the low immunogenicity of cancer antigens. Strategies to enhance antigen immunogenicity are discussed in a later section.

\section{Priming the Immune System}

DNA vaccines are simple vehicles for in vivo transfection and antigen production. A DNA vaccine is composed of a plasmid DNA that encodes the antigen of interest under the control of a mammalian promoter (i.e., CMV-intA, CMV immediate/early promoter, and its adjacent intron A sequence) and can be easily produced in the bacteria [23].

The optimized gene sequence of interest is delivered to the skin (intradermally), subcutaneum or to the muscle by one of several delivery methods. Using the host cellular machinery, the plasmid enters the nucleus of transfected local cells (such as myocytes or keratinocytes), including resident antigen presenting cells (APCs). Here, gene expression from plasmid is followed by generation of foreign antigens. Although the elucidation of all immunological components involved following DNA immunization has not been entirely achieved, the mode of action of plasmid DNA vaccines appears twofold. DNA plasmids, which are derived from bacteria, stimulate the innate immune system by interacting 
with Toll-like receptor 9 (TLR9) [24]), a receptor found on APCs, although the differential expression of TLR9 in mice and primate immune cells makes more complex their role as adjuvants in primates. This nonspecific immune response augments the antigen-specific immune response, where the direct and indirect presentations of antigen to APCs are involved. Two overarching models have been proposed. The antigen encoded by the plasmid is produced in host cells, either in professional APCs leading to direct priming of immune responses or in nonprofessional cells from where the antigen can be transferred to APCs leading to crosspriming.

A series of studies intended to determine how such vaccines could work investigated the source of Ag presentation, the immunological properties of the DNA itself, and the role of cytokines in eliciting the immune responses.

Early studies showed that DNA delivery method affected the cell types that were transfected. Gene Gun (bombardment of the epidermis with plasmid coated onto gold microbeads) tended to directly transfect epidermal keratinocytes and also Langerhans cells, which were shown to migrate rapidly to regional lymph nodes [25]. In this case, professional APCs were transfected directly and behave as the source of Ag presentation.

Alternatively, intramuscular injection of plasmid predominantly led to transfection of myocytes. Myocytes lack expression of major histocompatibility complex class (MHC) II and costimulatory molecules and thus would not be expected to prime $\mathrm{T}$ lymphocytes directly. Instead, immune priming likely occurs by dendritic cells (DCs) [26, 27] that presumably migrate to the site of DNA inoculation in response to inflammatory or chemotactic signals following vaccination $[28,29]$. These DCs are thought to present antigen by cross-presentation of extracellular antigen or following direct transfection of plasmid DNA $[26,30]$.

Thus, in terms of induction of immunity, there is an influence of the site and procedure used for injection, with muscle and skin cells clearly able to act as antigen depots but unable to prime the immune response. It is likely that cross-presentation from these sites to APCs is the major route to priming [26], but there is also evidence for direct transfection of APCs, especially when delivery is to skin sites through a gene gun [25]. The host-synthesized antigen is then processed and presented by APCs in the context of both MHC I and MHC II.

Antigen-loaded APCs travel to the draining lymph nodes, where they present peptide antigens to naïve T cells, thereby eliciting both humoral and cellular immune responses. Although plasmid DNA vaccines vectors can induce antibody and $\mathrm{CD} 4^{+} \mathrm{T}$ cell helper responses, they are particularly suited to induce $\mathrm{CD}^{+} \mathrm{T}$ cell responses because they express antigens intracellularly, introducing them directly into the MHC I antigen processing and presentation pathway [31].

Whatever, the process that conveys antigens to the APC seems highly efficient since DNA vaccines, that produce only very low levels of antigen, can induce all arms of the immune response [32].

One lesson learned in the last years is that the development of plasmid DNA as cancer vaccine raises key issues such as the need to break immunological tolerance, gradual loss of MHC and antigen in tumour cells, regulatory T cells that could negatively influence the induction of antitumour responses, systemic defects in dendritic cells, secretion of immunosuppressive cytokines, resistance to apoptosis [33, $34]$ as is discussed elsewhere.

\section{Advantages and Disadvantages of DNA Vaccines}

The use of DNA vectors represents an important platform for clinical applications, in which large-scale vaccine production is not easily manageable with other forms of vaccine including recombinant protein, whole tumor cells, or viral vectors [35].

Although viral mediated gene transfer by genetically modified lentiviruses, adenoviruses, adeno-associated viruses, and retroviruses is advantageous because of its high transfection efficiency and stability [36], the largest hurdles using viral vectors are to overcome the immunogenicity of the viral packaging proteins. Furthermore, viral methods are disadvantageous because of their high expense, toxic side effects, limits on transgene size, and potential for insertional mutagenesis [37].

On the one hand, nonviral vectors are highly flexible, are capable of encoding a number of immunological components, are associated with a lower cytotoxicity, are relatively more stable, and are potentially more cost-effective for manufacture and storage (Table 1).

Their safety in terms of adverse reactions after injection has been demonstrated in animal models $[38,39]$ as well as in human clinical trials.

The first clinical trail, initiated to monitor the safety and efficacy of a DNA vaccine against HIV-1 infection [40], demonstrated that DNA plasmid vaccines were safe and were capable of inducing detectable immune cellular and antibody responses [40-42].

The simple plasmid backbone coupled with the technology of gene manipulation allows incorporation of genes, which are then expressed by cells transfected in vivo. Although the transfection process is inefficient and varies with the target tissue and means of delivery, sufficient DNA is generally taken up to prime the immune response [32].

DNA vaccines are free of the problems associated with producing recombinant protein vaccines, and they are also safer than live attenuated which can cause pathogenic infection in vivo. Additionally, studies with DNA vaccines have shown that even after multiple immunizations, antiDNA antibodies are not produced [43].

The ability to introduce antigen to the host immune system, thus enabling it to elicit strong Th1 type $\mathrm{CD}^{+} \mathrm{T}$ cells and $\mathrm{CD}^{+}$cytotoxic $\mathrm{T}$ cells, is a unique feature of DNA vaccines which makes them distinct from conventional protein or peptide vaccines. Because of this feature, they can readily induce humoral as well cellular immune responses [44].

Plasmid-based gene transfer can also deliver oligonucleotides that can alter gene splicing or gene expression, for example, siRNA $[35,45]$. 
TABLE 1: DNA vaccines main features.

\begin{tabular}{llc}
\hline & Advantage & Drawback \\
\hline Design & $\begin{array}{l}\text { Allowing the introduction of several immunological } \\
\text { components; synthetic and PCR methods for simple } \\
\text { modifications }\end{array}$ & Low transfection efficiency \\
\hline Manufacture & $\begin{array}{l}\text { Rapid production and formulation; easily engineered, } \\
\text { reproducible, large-scale production and isolation }\end{array}$ & \\
\hline Safety & $\begin{array}{l}\text { No pathogenic infection in vivo; no significant adverse } \\
\text { events in any clinical trial; neutralizing immune } \\
\text { responses rarely observed; boost strategy is possible }\end{array}$ & $\begin{array}{c}\text { Lower immunogeni-city in larger animals and } \\
\text { human compared to mice }\end{array}$ \\
\hline Stability & $\begin{array}{l}\text { Long shelf life; relative temperature insensitivity; lack } \\
\text { necessity of a cold chain stored on a large scale }\end{array}$ &
\end{tabular}

\section{Enhancing Efficacy and Immunogenicity of DNA Vaccines}

Despite immunogenicity of DNA vaccines has been well established in animal models, low immunogenicity has been the major deterrent towards the development of DNA vaccines in large animal models and human. In order to overcome this hurdle, several approaches have been investigated including plasmid design, immunomodulatory molecules, delivery techniques, and prime-boost strategy (Table 2).

5.1. Plasmid Design. Early in the development of DNA vaccines, it became clear that maximizing the expression of the encoded Ag was critical to the induction of potent immune responses. Strong viral promoters, such as CMV-intA, are generally favoured over regulated or endogenous eukaryotic promoters [70]. Furthermore nuclear targeting sequence (NTS) could be introduced to increase the efficiency of nuclear plasmid uptake from cytoplasm after intramuscular injection $[48,71]$.

The utilization of codon-optimized sequences instead of the wild-type coding sequences is a general and potent method to improve vaccination. An optimal coding sequence is determined back from the amino acid sequence of the antigen by algorithms that take into account the abundance of specific tRNAs in the cytosol of human cells and the predicted structure of the mRNA. Thereafter the selected gene sequence is constructed in vitro using synthetic oligonucleotides. Adverse rare codons are avoided and secondary structures in the mRNA are minimized. Thereby, the synthetic gene is optimal for expression and consequently for the induction of an immune response [72].

The flexibility of plasmid design coupled with the technology of gene manipulation allows also "gene optimization." Indeed, the variable regions of the heavy $\left(V_{H}\right)$ and light chain $\left(V_{L}\right)$ of the tumor immunoglobulin, specific for the B-cell malignancies, can be readily cloned and combined into single-chain variable fragment ( $\mathrm{scFv}$ ) format, encoding a single polypeptide consisting of $V_{H}$ and $V_{L}$ genes linked together in frame by a short 15-amino acid linker [73].
As already discussed, the backbone of bacterial DNA includes cytosine-phosphate-guanine $(\mathrm{CpG})$ unmethylated regions as sequence motifs that stimulate innate immunity, creating an inflammatory milieu for triggering the adaptive immune response [74]. The role of CpG motifs as adjuvants of immune response to DNA vaccines is well documented in mice [75]. Preclinical studies showed that the addition of CpG motifs in the plasmid can result in the induction of proinflammatory cytokines, for example, IL-12 or IFNI [75]. CpGs are recognized by TLR9, a receptor found on APCs, helping cytotoxic T-lymphocyte (CTL) differentiation and priming. The coadministration of genes encoding ligands for Toll-like receptors (TLRs) or their signaling molecules has been shown to improve the immunogenicity of DNA vaccines $[66,76]$.

Engineering DNA vaccine design for maximizing epitope-specific immunity has allowed epitope enhancement by sequence modification. The recent molecular understanding of the immune response is leading to new strategies to induce more effective immune responses. Self-tolerance might lead to deletion of T cells specific for the most effective epitopes, leaving only low-avidity T cells $[77,78]$. Therefore, not all sequences are optimal antigenic epitopes. A process termed epitope enhancement is expected to make the sequences of many epitopes of cancer more immunogenic [79]. Epitope sequences can be modified to increase the affinity of the epitope peptide for the MHC molecule. The knowledge of sequence motifs for peptide binding is the key to improve the primary and/or secondary "anchor residues" that provide much of the specificity of binding to the MHC molecule $[80,81]$. This strategy can greatly increase the potency of a vaccine and can convert a subdominant epitope into a dominant one by making it more competitive for available MHC molecules, thereby increasing the level of specific peptide-MHC complexes on the antigen presenting cell surface [82]. Epitope enhancement has been used to increase the affinity for both MHC class I and class II molecules (reviewed in [83]).

To enhance the immunogenicity of DNA, vaccines encoding immunostimulatory RNA, such as double-stranded RNA or replicon RNA, were also generated [84]. 
Table 2: DNA Vaccine Enhancing Strategies.

\begin{tabular}{|c|c|c|c|}
\hline Strategy & Approach & Indication & References \\
\hline \multirow{6}{*}{$\begin{array}{l}\text { Routes of } \\
\text { administration }\end{array}$} & intramuscular/EP & $\begin{array}{l}\text { prostate cancer; B-cell } \\
\text { lymphoma }\end{array}$ & {$[46-48]$} \\
\hline & intradermal/EP & $\begin{array}{l}\text { prostate cancer; colon } \\
\text { cancer }\end{array}$ & {$[49,50]$} \\
\hline & gene gun & cervical cancer & {$[51,52]$} \\
\hline & tattoo perforating needle & melanoma & {$[53]$} \\
\hline & intratumor & $\begin{array}{l}\text { melanoma; renal } \\
\text { carcinoma }\end{array}$ & {$[54,55]$} \\
\hline & high-pressure liquid delivery & $\begin{array}{l}\text { B-cell lymphoma; } \\
\text { colon cancer }\end{array}$ & {$[50,56]$} \\
\hline \multirow{5}{*}{$\begin{array}{l}\text { Genetic } \\
\text { immunomodulators } \\
\text { as Adjuvants }\end{array}$} & cytokine & $\begin{array}{l}\text { liver cancer; prostate } \\
\text { cancer; melanoma; B-cell } \\
\text { lymphoma }\end{array}$ & {$[56-62]$} \\
\hline & chemokine & B-cell lymphoma & {$[63]$} \\
\hline & $\mathrm{T}$ cell helper epitopes & $\begin{array}{l}\text { prostate cancer; follicular } \\
\text { lymphoma; colon } \\
\text { carcinoma }\end{array}$ & {$[46,47,64,65]$} \\
\hline & Toll-receptor ligands & lung carcinoma & {$[66]$} \\
\hline & heat shock proteins & cervical cancer & {$[67]$} \\
\hline \multirow{4}{*}{ Prime-boost strategy } & plasmid DNA/plasmid DNA+EP & $\begin{array}{l}\text { prostate cancer; colon } \\
\text { cancer }\end{array}$ & {$[46,47,50]$} \\
\hline & $\begin{array}{l}\text { plasmid DNA/recombinant } \\
\text { protein }\end{array}$ & $\begin{array}{l}\text { prostate carcinoma; breast } \\
\text { cancer }\end{array}$ & [68] NCT00363012 \\
\hline & plasmid DNA/viral vector & $\begin{array}{l}\text { liver cancer; melanoma; } \\
\text { prostate carcinoma }\end{array}$ & {$[58,60,69]$} \\
\hline & viral vector/plasmid DNA & prostate cancer & {$[59]$} \\
\hline
\end{tabular}

Engineering vaccine design for manipulating antigen presentation and processing pathways is one of the most important aspect that can be easily handled in the DNA vaccine technology. If an antibody response is the goal, it is clearly desirable to direct antigen expression to the endoplasmic reticulum (ER), in which folding and secretion can occur. An appropriate leader (signal) sequence can achieve this. (reviewed in [47]). For induction of CTLs, addition of genes encoding molecules such as ubiquitin, aimed to enhance degradation and peptide production in the proteasome, can be effective (reviewed in [85]). Similarly, targeting expression to different subcellular pathways such as the endosome or lysosome can amplify $\mathrm{CD} 4^{+} \mathrm{T}$ cell responses [85]. Thus, DNA vaccines can be designed to induce an appropriate effector pathway, including antibody against cell-surface antigens, or CTL response against intracellular antigens expressed only as MHC class I-associated peptides. Since tumor antigens are often weakly immunogenic and the immune repertoire in patients may have been tolerized, the central question is whether DNA vaccines can activate and maintain the high level of immunity required to suppress cancer cell growth.

The pivotal position of CD4 Thelper (Th) cells in helping $\mathrm{B}$ cells to produce antibody and control induction and maintenance of CD8 T cells [86] has led some investigators to focus on their importance in responses to DNA vaccination. By selecting genes encoding microbial proteins fused to the tumor antigen sequence, it was possible to activate Th cells and to dramatically amplify immunity against tumor cells [87]. As discussed in the following section, DNA vaccines offer the opportunity to activate Th cells and transform weak and ineffective immunity to a powerful antitumor attack [88].

5.2. Immunomodulatory and Immunoenhancing Molecules. Even though specific antibody and CTL responses could be induced in clinical trials with naked DNA vaccines, by the intramuscular or intradermal route, high doses of DNA were necessary to elicit detectable immune responses $[89,90]$. Large quantities, that is, $5-10 \mathrm{mg}$, are required to induce only modest immunogenicity [91].

Modifying the microenvironment of the vaccinated site by coadministration of genetic, that is, DNA plasmids coding for immunostimulatory molecules, protein, or chemical adjuvants, improves the low immunogenicity of DNA vaccines [31].

Progress has been made in developing improved techniques for encapsulating plasmid DNA (liposomes, polymers, and microparticles) although few of these formulations have been shown to elicit immune responses that are superior to those elicited by simple intramuscular plasmid DNA, still disappointing in human clinical trials [92].

Considering the ease in design and construction of plasmid DNA used to target a particular neoplasm, biological 
TABLE 3: Adjuvant molecules employed in cancer clinical trials to enhance the immune response.

\begin{tabular}{|c|c|c|c|}
\hline & Adjuvant & Phase & References \\
\hline \multirow{5}{*}{ Genetic } & cytokines & \multirow{2}{*}{ I/II-II } & NCT00019448 \\
\hline & (GM-CSF, IL-12, IL-2) & & {$[56,62]$} \\
\hline & bacterial toxins & \multirow{2}{*}{$\mathrm{I} / \mathrm{II}$} & \multirow{2}{*}[46,47,64,65]{} \\
\hline & (pDOM/tetanus toxin $\mathrm{FrC}$ ) & & \\
\hline & $\begin{array}{l}\text { immunomodulatory } \\
\text { molecules (HSP70) }\end{array}$ & $\mathrm{I} / \mathrm{II}$ & {$[67]$} \\
\hline Protein & cytokines (GM-CSF, IL-2) & I/II-II & {$[58,59,61]$} \\
\hline
\end{tabular}

adjuvants can be tailored and encoded within the same DNA vector as well [35]. A vast array of molecules able to modulate immune responses can be delivered (Table 3 ).

They include chemokines to attract APC [93], activating cytokines [94, 95], costimulatory molecules, APC-targeting antibodies, and molecules to manipulate antigen presentation and/or processing [96].

One of the common cytokines employed in plasmid DNA vaccine is granulocyte-macrophage colony-stimulating factor (GM-CSF), a molecule able to enhance immune responses by inducing proliferation, maturation, and migration of DCs as well as expansion and differentiation of B and T lymphocytes [62].

In addition to codelivery, DNA vaccines allow fusion of genes encoding activating molecules to the antigen-encoding sequence. This is an advantage, and fusion genes can create single vaccines capable of multiple functions.

Biragyn and colleagues showed that the efficiency of DNA vaccination in vivo could be greatly increased by encoding a fusion protein consisting of scFv fused to a proinflammatory chemokine moiety that facilitates targeting of APCs for chemokine receptor-mediated binding, uptake, and processing of $\mathrm{scFv}$ antigen for subsequent presentation to $\mathrm{CD}^{+}$or $\mathrm{CD}^{+} \mathrm{T}$ cells, or both [63]. In two independent models, vaccination with DNA constructs encoding a fusion protein consisting of $\mathrm{scFv}$ fused to the monocyte chemotactic protein 3 (MCP-3) or the interferon inducible protein 10 (IP-10a) generated superior protection against a large tumor challenge (20 times the minimum lethal dose), as compared with the best available protein vaccines [63].

Additional strategies to activate effective immunity against poorly immunogenic tumor antigens employ the "DNA fusion genes vaccines" to activate T cell help for antitumor responses. The $\mathrm{CD} 4^{+} \mathrm{Th}$ cell, as pivotal cell of the immune response able to induce high levels of immunity and the maintenance of the response, has been extensively studied by Stevenson and coworkers [97]. The requirement for foreign sequences to induce Th for the B-cell response and to help the CTL response has been known for many years [98, 99]. Since Th cells control responses to vaccination, it is quite obvious that self-antigens, which do not contain epitopes likely to be recognized by available Th cells, are incapable of inducing immunity. A strategy to activate Th cells for inducing antitumor immunity is to engage a repertoire against nontolerized antigens. The use of xenogeneic antigen to break tolerance is likely due to the presence of some foreign sequences in the xenogeneic antigen that are able to activate Th cells [100]. Focusing on the antimicrobial repertoire, the principle has been applied to realize the DNA fusion gene vaccines encoding the tumor antigen linked to an antigen derived from tetanus toxin. Fusion of the Fragment $\mathrm{C}$ ( FrC) of tetanus toxin amplified the immune response against a range of tumor antigens, leading to suppression of tumor growth [87]. Clinical trials by using these approaches to breaking self-tolerance for therapeutic purposes in patients with lymphoma and prostate carcinoma are discussed elsewhere.

5.3. Route of Administration. It is increasingly apparent that the immunogenicity of DNA vaccines greatly depends upon the delivery methods used for immunization [101].

In a melanoma mouse model, DNA vaccination was administered together with intratumoral delivery of antiangiogenic plasmids, encoding angiostatin, and endostatin. Combined melanoma vaccination resulted in 57\% tumorfree survival over 90 days after challenge [54]. In a modest proportion of patients with malignant disease, intratumoral injection of DNA led to regression of tumor at distant sites [102].

The recent studies have confirmed that physical methods are superior over other delivery methods that administer DNA in various chemical solutions $[103,104]$.

Biolistic gene gun delivery involves adhering naked DNA to gold beads and shooting the particles through a highpressured instrument. This system delivers DNA directly into skin and Langerhans cells in a highly efficient process. Gene gun immunization has been shown to induce a greater $\mathrm{CD}^{+} \mathrm{T}$ cell response as well as to require less vaccine to achieve tumor immunity [51].

A promising strategy is electroporation (EP), which in primates increases not only the level but also the breadth of response [105], overcoming the difficulty in translating the effectiveness of DNA vaccination from preclinical rodents to large animals, including human subjects [106].

Electroporation-based DNA delivery technology dramatically enhances cellular uptake of DNA vaccines. EP itself works as an adjuvant to enhance the necessary "danger signals" that become detectable by the immune system. The tissue damage caused by the application of EP causes inflammation and recruits DCs, macrophages, and lymphocytes to the injection site $[107,108]$ inducing significant immune responses, including antibody and T-cell responses. Moreover, it is tolerable without anesthetic and does not induce unwanted immune responses against the delivery mechanism, therefore it can be used for repeat administrations.

A newly developed intradermal DNA delivery is the tattoo technology. The tattoo device has a cartridge of nine fine metal perforating needle that oscillate at a constant high frequency and puncture the skin, leading to DNA transfer to skin-associated cells. The expression of reporter genes results in robust T-cell responses [109]. Recently tattooimmunization was applied in a phase I study to assess 
the toxicity and efficacy of inducing tumor-specific T-cell immunity against melanoma [53].

5.4. Prime-Boost Strategies. Vaccination schedules based on combined prime-boost regimens using different vector systems to deliver the desired antigen (i.e., heterologous primeboost immunization regimen) appear to be a successful improvement in DNA vaccine platform.

Actually, prime-boost regimens have shown promise in eliciting greater immune response in humans compared with DNA vaccination alone [101].

The DNA-prime-viral vector-boost approach focuses on the induction of T-cell immune responses. In this approach, homologous boost immunization carries the equivalent antigen than the previous immunization. Viral vectors that have been tested as booster vaccine include adenovirus, vaccinia virus, fowlpox $[110,111]$ as well as recombinant vesicular stomatitis virus [112].

Likewise, the DNA-prime-protein-boost approach employs recombinant protein antigens that match with the antigens used in DNA prime immunization $[68,113,114]$. This strategy aims to develop balanced humoral and cellmediated immune responses with a focus on eliciting high quality protective antibody responses.

The heterologous prime-boost vaccination regimen exploits the ability of the immune system to generate a large number of secondary antigen-specific $\mathrm{T}$ cells. Following a priming immunization, a proportion of the antigenspecific $\mathrm{T}$ cell population transforms into antigen-specific memory $\mathrm{T}$ cells, which have the ability to expand rapidly upon encounter with the same antigen a second-time round.

Since the priming and boosting vectors are different, this strategy allows for greater expansion of the disease antigen-specific $T$ cell populations [115]. To date, heterologous prime-boost regimens are among the most potent strategies to induce cellular immune responses. Compared to homologous prime-boost approach with the same DNA vaccine, boosting a primary response with a heterologous vector will result in 4-10-fold higher T cell responses [116118].

On the one end, a combination of DNA vaccines with EP in a homologous prime-boost approach could generate antibody responses comparable to those that are induced by protein in Complete Freund Adjuvant, and also amplified CTL responses [46]. EP may provide a prime-boost combination equivalent to that observed using viral vectors, and it is now undergoing testing in the clinic using a DNA vaccine for patients with prostate cancer. Repeated EP has been accepted by patients without the need for general or local anaesthesia and with no apparent long-term ill effects [47].

5.5. Strategies to Break the Immunosuppressive Networks. Immune suppression is a feature of the tumor microenvironment and a barrier to tumor immune therapy. The microenvironment of tumors is established through the activity of both myeloid and lymphoid regulatory cells, as well as through the production of immune-suppressive factors by malignant cells themselves.

Many tumor-infiltrating macrophages, referred to myeloid-derived suppressor cells (MDSCs), have an immune-suppressive phenotype [119]. These macrophages are abundant in many tumors arising in both humans and mice and can exert powerful anti-inflammatory effects. In addition to MDSCs, regulatory $\mathrm{T}$ cells (Tregs) also heavily infiltrate many tumors [120]. These cells, characterized by the expression of the transcription factor FoxP3 as well as CD4 and CD25, play a key role in the regulation of adaptive immunity. Tregs can suppress immune responses through the secretion of suppressive cytokines like TGF- $\beta$ and IL$35[120,121]$. Tregs are a potential barrier to developing productive immune therapies for cancer, and they represent an attractive target for enhancing antitumor immunity.

Cancer immunotherapy is designed to specifically target cancer types using components of the immune system. Therefore DNA vaccines are also faced many obstacles that include breaking peripheral $\mathrm{T}$ cell tolerance against tumor self-antigens, to elicit appropriate immune reactions, as well as overcoming tumor-derived immunosuppressive networks and evasion tactics. Evasive mechanisms adopted by malignant cells to prevent immune cell function are numerous and lead to the clonal expansion of non-immunogenic tumor cells, by loss of tumor antigen, and to the apoptosis prevention [35].

Tumour cells can downregulate expression of MHC and target antigens and often secrete immunosuppressive molecules to defend themselves against attack [122]. Tumours can create a tolerogenic environment which spreads to draining lymph nodes and can enhance regulatory $\mathrm{T}$ cell activity. The hurdles to successful reversal of tolerance and induction of effective immunity are becoming clear and vaccines must incorporate elements to overcome them [123].

Furthermore cancer cells secrete soluble factors in the tumor microenviroment, for example, VEGF, IL-10, and TGF- $\beta$, that affect the maturation, differentiation, and activity of APCs as DCs [124], interfering with immune cells maturation and effector properties. The tumour microenvironment may drive tumour growth and even selectively support a subset of tumour cells, the cancer stem cells (CSCs).

The DNA vaccination platform can be capable of suppressing the progression of already established tumor by targeting those secreted soluble factors in the tumor microenvironment [125], reversing immunological attenuation mechanisms and improving DNA vaccine potency.

The concept of combining cancer vaccination with angiogenesis inhibition is appealing, due to favorable safety profile of both approaches, as well as possible biological synergies [54]. DNA vaccination in mice against the VEGF receptor, FLK-1, abrogated the tumor vasculature and protected DNA vaccinated animals from tumor challenge in prophylactic approach [126]. Expression of the plateletderived growth factor receptor (PDGFR) in stromal cells directly correlates with advanced stage disease in human colorectal cancer. DNA vaccine against PDGFR $\beta$ suppressed 
growth and dissemination of human colorectal cancer cells injected into mice [127].

In vivo coadministration of plasmids encoding the chemokine macrophage inflammatory protein-1alpha (MIP1alpha) and the DC-specific growth factor fms-like tyrosine kinase 3 ligand (Flt3L) with the plasmid DNA augments the immunogenicity of the vaccine, mobilizing and activating large numbers of DCs at the site of inoculation [128].

Consistent with the concept that most effective cancer therapies are multimodal, combining Treg depletion with active cancer immunotherapeutic interventions is an attractive prospect, supported by abundant data in mice [129132] and by preliminary human trials [133-135]. Lastly, additional strategies aimed to altering regulatory $\mathrm{T}$ cell function in cancer immunotherapy, including blocking Treg trafficking, differentiation, and/or function and reducing effector cell susceptibility to suppression, have already proven successful in preliminary studies [136-138].

\section{Human Clinical Trials}

The goals of the various clinical trials were to demonstrate the safety and tolerability of the candidate vaccines, and to explore the efficacy of DNA vaccines in humans. Injection of the plasmid DNA construct is tolerated well in terms of safety in the patient population and rarely involves systemic toxicities. DNA vaccines that are currently being tested do not show relevant levels of integration into host cellular DNA [139, 140]. Besides, preclinical studies in nonhuman primates as well as early studies in humans did not detect increases in antinuclear or anti-DNA antibodies. Participants in human trials of DNA vaccines are followed for possible signs and symptoms of autoimmunity induced by DNA vaccination giving no convincing evidence of autoimmunity developing in association with a DNA vaccine $[40,42,141]$.

The earliest Phase I clinical trial for a DNA vaccine was of an HIV-1 candidate tested in individuals infected by HIV1 , followed by studies in volunteers who were not infected by HIV-1 [40]. Other prophylactic and therapeutic DNA vaccine trials followed, including trials that tested DNA vaccines against cancer influenza, malaria, hepatitis B, and other HIV-1 candidates [24, 41, 42]. These trials demonstrated that the DNA vaccine platform is well tolerated and safe, as no adverse events were reported and all studies went to completion.

The evident safety of DNA vaccines has led to a relaxation of the requirements for approval by both the United States Food and Drug Administration and the national competent regulatory authorities in Europe. This is why many clinical studies tend to melt the first phase with the second phase. Then the issue has become the efficacy rather than toxicity.

Since tumour antigens are generally weakly immunogenic, they often induce a low level of spontaneous immunity or, in other cases, the spontaneous response can lead to tolerance [47]. The molecular precision offered by genebased vaccines, together with the facility to include additional genes to direct and amplify immunity, could lead to an efficient methods to use the immune system against cancer.
The inclusion of FrC sequence, or other nonself antigens, activates T-cell help to reverse tolerance and induces high levels of immunity $[47,64,65]$. To further increase immunogenicity of DNA vaccine, the use of molecular adjuvants such as cytokines and immunomodulatory molecules has been extensively employed in clinical trials $[56,58-63,67]$.

Clinical trials conducted over the last few years have led promising results, particularly when DNA vaccines were used in combination with other form of vaccines, as demonstrated in prostate and liver cancer clinical trials [58$60,68]$. Delivery of gene-based vaccines by physical methods, that is, electroporation and gene gun, has demonstrated to amplify the immune responses induced by therapeutic vaccines against cancer $[46,47,64]$.

In the following section, an overview of various types of clinical trials will be given to highlight the issue for usage of plasmid DNA in humans. Table 4 provides a brief summary of clinical trials discussed in this review.

6.1. Lymphoma. DNA vaccination is an attractive and effective approach for active therapeutic vaccination against Bcell malignancies given the ease of production compared to Id protein vaccines.

Patient-specific DNA vaccines for therapy of B cell lymphomas and multiple myelomas based on $\mathrm{scFv}$ encoding a chimeric immunoglobulin molecule consisting of $V_{H}$ and $V_{L}$ genes derived from each patients's tumor were shown to be effective in animal models $[47,73]$.

The first phase I/II trial of idiotypic vaccination for follicular B-cell lymphoma using a genetic approach [142] was conducted by Hawkins and colleagues. Vaccines encoding individual DNA idiotypic scFv fused to TTFrC were delivered as naked DNA by i.m. injection in patients with follicular lymphoma in clinical remission following chemotherapy, and plasmid DNA were able to develop cellular or/and humoral antiidiotype immune responses in 38\% of patients over a period of several months [47].

In a second study of vaccine therapy for B-cell lymphoma, the patient's tumor scFv was linked to the IgG2a and $\kappa$ mouse immunoglobulin heavy- and light-chain constant regions chains, respectively. In this phase, I/II trial patients in remission after chemotherapy received two series of i.m. DNA vaccinations and at the end of the second vaccination, $50 \%$ of patients exhibited humoral and/or T-cell anti-Id responses; yet, these were cross-reactive with Id proteins from other patient's tumors. Subsequently, a third series of vaccinations was carried out using human GM-CSF DNA mixed with Id DNA: humoral or T-cell responses were boosted in some cases [56].

6.2. Prostate Carcinoma. After the important insights provided in preclinical studies [49], the department of Oncology of the University Hospital of Uppsala is recruiting participants for a phase I/II trial, where intradermal EP (DERMA VAX) will be used as a delivery system. This study will assess the feasibility and safety of vaccination with increasing doses of xenogenic DNA coding for the Rhesus Prostate Specific Antigen (rhPSA), a protein that is $89 \%$ homologous to 
human PSA, administered in patients with relapsed prostate cancer.

A phase I/II, dose escalation, DNA vaccination trial with plasmid DNA, which carries prostate-specific membrane antigen (PSMA), fused to a domain (DOM1) of Fragment $\mathrm{C}$ of tetanus toxin, delivered either by i.m. or by i.m. followed by EP, was performed in patients with recurrent prostate cancer. The epitope used in this study, $\mathrm{PSMA}_{27}$ is a short stretch of 9 amino acids tumor-derived epitope belonging to the PSMA. Preliminary analysis of $\mathrm{CD}^{+} \mathrm{T}$ cell reactivity against the prostate-specific membrane antigen target peptide indicated significant responses in 3 out of 3 patients and $\mathrm{CD}^{+}{ }^{+} \mathrm{T}$-cell responses against the DOM1. These data validated EP as a potent method for stimulating humoral responses induced by DNA vaccination in humans $[46,47,64]$.

Results of a phase I/II trial, conducted with DNA vaccine encoding human prostatic acid phosphatase (PAP) coadministered intradermally with GM-CSF, in prostate cancer patients (stage D0) are associated with an increased PSA doubling time (PSADT), 6.5 months pretreatment versus 9.3 months in the 1 year posttreatment [61]. A longer PSADT is associated with an extremely low risk of death from prostate cancer. Besides, $14 \%$ of patients developed PAP-specific IFN gamma-secreting $\mathrm{CD} 8^{+} \mathrm{T}$-cells immediately after the treatment course, and $41 \%$ of patients developed PAPspecific $\mathrm{CD}^{+}$and/or $\mathrm{CD} 8^{+} \mathrm{T}$-cell proliferation, confirming the preclinical studies [143].

Todorova and colleagues [58] enhanced the DNA vaccine efficacy by heterologous prime-boost regimen in a Phase I/II study. Prostate cancer patients were prime-boosted with alternate injections of recombinant adenoviral vector expressing PSMA and plasmid DNA encoding PSMA and CD86 alongside receiving GM-CSF proteins as adjuvants. After 36-month observation period from the first vaccine injection, $86 \%$ of participants developed anti-PSMA antibody.

6.3. Melanoma. DNA vaccine platform is a promising therapeutic approach also for the treatment of malignant melanoma, as demonstrated by already completed and ongoing clinical trials.

In stage IV melanoma patients, a phase I/II pilot study of intranodal delivery of Synchrotope MA2M plasmid DNA vaccine induced both humoral and CTL responses against cells expressing tumor two melanoma-associated antigens [144]. Synchrotope MA2M plasmid is a bivalent DNA vaccine encoding epitopes for both Melan-A (MART-1) and tyrosinase with potential antineoplastic activity.

The same approach was used in a improved trial conducted with the Synchrovax SEM plasmid DNA vaccine containing a plasmid pSEM that encodes 4 peptide epitope sequences, Melan-A (26-35), Melan-A (31-96), tyrosinase (1-9), and tyrosinase (369-377), resulting in antigen-specific immunity even though not induce regression of established disease [145].

DNA plasmids encoding the gp100 nonmutated melanoma-melanocyte antigen alone were administered in patients with metastatic melanoma. Rosenberg et al. showed that neither intramuscular nor intradermal injection was capable of raising cellular immune reactivity or a significant incidence of antitumor effects [57]. Increasing results were obtained in a phase II study with interleukin- 2 cytokines as adjuvant used in combination with same vaccination protocols (ClinicalTrials.gov Identifier: NCT00019448) and in a phase II trial with human GM-CSF plasmid DNA in conjunction with a multipeptide vaccine encoding gp100 and tyrosinase peptidse [62].

6.4. Cervical Cancer. Current vaccination strategies are based on the induction of neutralizing antibodies against the major and minor capsid proteins, L1 and L2, of human papillomavirus, and Gardasil is only effective against a subset of HPV genotypes [146]. Further therapeutic interventions for early-stage and late-stage cervical cancers or HPV-related disease are uneffective.

DNA plasmid platform could represent an ideal vaccine against HPV infections since it could generate both humoral immune response to prevent new infections as well as cellmediated immunity to eliminate established infection [146].

A recent phase I/II clinical trial in patients with high-grade squamous intraepithelial lesion associated with HPV16 provided DNA plasmid expressing a mutated nonfunctional E7 incapable of binding retinoblastoma protein, with no transforming activity, linked to HSP70. A signal sequence was also attached to the hybrid antigen which results in secretion of the linked E7 antigen [67]. E7 HPV antigen as well as E6 antigen are essential for transformation and are coexpressed in HPV-associated lesions hence they represent ideal targets for the development of HPV therapeutic vaccines.

6.5. Liver Cancer. In preclinical studies, mice were successfully DNA-based immunized [147]. In a prime-boost approach, coadministration of plasmids DNA encoding murine alpha fetoprotein (AFP) and murine GM-CSF was followed by boosting with an AFP-expressing nonreplicating adenoviral vector [60] leading to tumor protective immunity.

The early studies were applied in a phase I/II clinical trial in patients with HLA-A*0201-expressing stage II-IVA hepatocellular carcinoma. Vaccine therapy, comprising AFP and sargramostim (GM-CSF) plasmids DNA, followed by AFP adenoviral vector boost determined the dose-limiting toxicity and maximum tolerated dose of adjuvant vaccination (ClinicalTrials.gov Identifier: NCT00093548).

6.6. Breast Cancer. Since HER-2/neu (HER2) oncogenic protein is a tumor antigen in patients with breast and ovarian cancer, several vaccine strategies have been developed and are being evaluated for safety and immunogenicity in phases I and II clinical trials (ClinicalTrials.gov). Patients whose tumors overexpress the antigen have both detectable antibody and T-cell immunity directed against HER2. Likewise preclinical studies suggest that the HER2 protein, particularly the intracellular domain (ICD), is a tumor rejection antigen [148]. 
TABLE 4: Phases I/II-II clinical trials: key summary.

\begin{tabular}{lcclcl}
\hline Tumor & Study ID & Patients no. & Objectives & Status & Response \\
Lymphoma & UK-007 & 25 & $\begin{array}{l}\text { Determine the safety, } \\
\text { dose, immunogenicity }\end{array}$ & Completed & $\begin{array}{l}\text { Absence of toxicity } \\
\text { Cellular and/or } \\
\text { humoral responses }\end{array}$ \\
\hline
\end{tabular}

Determine the feasibility and safety

NCT00859729

18

UK-112

20

Determine the safety and functionality of DNA vaccine delivery system

Determine the feasibility and safety

Determine the immunological responses

Prostate cancer

NCT00582140 $22 \quad$ Determine the safety

Completed

(Aug 2009)

\begin{tabular}{|c|c|c|c|c|}
\hline & $\begin{array}{c}\text { Bulgarian } \\
\text { Drug } \\
\text { Agency Register }\end{array}$ & 52 & $\begin{array}{l}\text { Characterize the humoral } \\
\text { immune response } \\
\text { against PSMA }\end{array}$ & Completed \\
\hline \multirow[t]{3}{*}{ Melanoma } & NCT00033228 & $6-18$ & $\begin{array}{l}\text { Determine the safety } \\
\text { and tolerability } \\
\text { Determine the } \\
\text { immunological and } \\
\text { clinical responses }\end{array}$ & $\begin{array}{l}\text { Completed } \\
\text { (July 2009) }\end{array}$ \\
\hline & & & $\begin{array}{l}\text { Determine the safety } \\
\text { and tolerability }\end{array}$ & $\begin{array}{l}\text { Open } \\
\text { Not }\end{array}$ \\
\hline & NCT00085137 & $3-27$ & $\begin{array}{l}\text { Determine any } \\
\text { antitumor response }\end{array}$ & Recruiting \\
\hline \multirow[b]{2}{*}{ Cervical cancer } & & & $\begin{array}{l}\text { Determine the feasibility } \\
\text { and toxicity } \\
\text { Determine the effect } \\
\text { Determine changes } \\
\text { in lesion size and } \\
\text { HPV viral load }\end{array}$ & $\begin{array}{l}\text { Open } \\
\text { Not }\end{array}$ \\
\hline & NCT00121173 & 150 & $\begin{array}{l}\text { Determine the immune } \\
\text { responses } \\
\text { Correlate measures of } \\
\text { immune response with } \\
\text { clinical response }\end{array}$ & Recruiting \\
\hline
\end{tabular}

Determine the dose-

limiting toxicity and maximum tolerated dose

Immunity

T-cell response

\begin{tabular}{|c|c|c|c|c|c|}
\hline & & & $\begin{array}{l}\text { Determine the dose- } \\
\text { limiting toxicity and } \\
\text { maximum tolerated dose }\end{array}$ & & \\
\hline Liver cancer & NCT00093548 & $3-25$ & $\begin{array}{l}\text { Determine the optimal } \\
\text { biological dose } \\
\text { Determine disease-free } \\
\text { survival of patients treated }\end{array}$ & $\begin{array}{c}\text { Completed } \\
(\text { Feb 2009) }\end{array}$ & $\begin{array}{l}\text { Absence of } \\
\text { toxicity }\end{array}$ \\
\hline Breast cancer & NCT00363012 & 56 & $\begin{array}{l}\text { Determine and } \\
\text { characterize } \\
\text { the immunologic } \\
\text { memory } \\
\text { to the HER2-ICD }\end{array}$ & $\begin{array}{c}\text { Open } \\
\text { recruiting }\end{array}$ & $\begin{array}{l}\text { Absence of } \\
\text { toxicity }\end{array}$ \\
\hline
\end{tabular}

Absence of

toxicity

In the highest-dose

cohort the number

of patients with

complete histologic

regression is

higher than the

Transient

unvaccinated cohort,

but not significant.

injection-site

discomfort
Brief and

acceptable

pain at the

injection site

ecific IFN

CD4+ and/or CD8+

T-cell proliferation

Antigen-specific

established disease

Grade I/II toxicity

Grade I toxicity 
Salazar and colleagues are studying the immune response in patients overexpressessing HER2 epitope who have undergone vaccine therapy in a heterologous prime-boost regimen (ClinicalTrials.gov identifier: NCT00363012). After vaccination with a plasmid encoding HER2 ICD in patients with advanced stage HER2 overexpressing breast and ovarian cancers patients receive HER2 ICD protein treatment intradermally at 6 months postvaccination with the pNGVL3hICD vaccine. The injection site is biopsied and examined for infiltrating T-cell and antigen-presenting cell populations and blood samples are examined for the presence of memory markers to demonstrate the development of HER2 ICD memory immunity.

\section{Conclusions and Future Directions}

Plasmid DNA is a new generation biotechnology product that is just beginning to enter the marketplace. Progress in the application of DNA vaccines as an immunization protocol is evident from the increasing number of such vaccines under evaluation in clinical trials and by the recent approval of several DNA vaccine products for veterinary applications.

The goal of DNA vaccination will be the development of effective immunization strategies against previously established tumors. Because of tolerance to tumour antigens, efforts are ongoing to optimize the DNA vaccine technology platform. Strategies to improve antigen expression, inclusion of adjuvants in the formulation, or as immune modulators to improve the immunogenicity, and the use of next-generation delivery methods are under intensive investigation. Current effort to prioritize cancer antigens represents the logical next step in attempting to focus translational efforts on the most promising cancer antigens into vaccines for cancer treatment or prevention. It is likely that these vaccines will have to be combined with other treatment modalities. It has become appreciated that vaccine approaches may enhance subsequent responses to radiotherapy and that certain chemotherapies actually enhance responses to vaccines. Accordingly, several late-stage clinical trials are already evaluating the benefit of vaccination in addition to conventional chemotherapy. One attractive setting is in patients during complete remission after standard adjuvant treatment (chemotherapy, radiotherapy, etc., or a combination) to whom vaccination can be given after immunological recovery [149]. Combining immunotherapy with conventional chemotherapy, antiangiogenic therapy, and other approaches could yield synergistic or additive therapeutic results.

There is still much to do in terms of optimizing vaccine design, activation and selecting appropriate target antigens, improving immune recruitment, and delivery technology. Nevertheless, in the next years an increasing number of DNA vaccines will enter more advanced phases of human studies, aimed to establish their efficacy as real clinical products. Therapeutic regimens composed of optimal vaccine formulations with combinations of immunotherapy agents and delivery strategies could offer hope to patients suffering from incurable cancer that current standard therapies cannot provide alone.

\section{Acknowledgments}

This work was supported by MUR Grant FIRB 2006 (RBIP0695BB), and by the Italian Banca Marche. D. Fioretti and S. Iurescia. have been supported by MUR Grant FIRB 2006 (RBIP0695BB). Both of them contributed equally to the preparation of this paper.

\section{References}

[1] S. A. Hoption Cann, J. P. Van Netten, and C. Van Netten, “Dr William Coley and tumour regression: a place in history or in the future," Postgraduate Medical Journal, vol. 79, no. 938, pp. 672-680, 2003.

[2] J. Ferlay, P. Autier, M. Boniol, M. Heanue, M. Colombet, and P. Boyle, "Estimates of the cancer incidence and mortality in Europe in 2006," Annals of Oncology, vol. 18, no. 3, pp. 581592, 2007.

[3] H. Varmus, "The new era in cancer research," Science, vol. 312, no. 5777, pp. 1162-1165, 2006.

[4] J. A. Wolff, R. W. Malone, P. Williams, et al., "Direct gene transfer into mouse muscle in vivo," Science, vol. 247, no. 4949, pp. 1465-1468, 1990.

[5] J. B. Ulmer, J. J. Donnelly, S. E. Parker, et al., "Heterologous protection against influenza by injection of DNA encoding a viral protein," Science, vol. 259, no. 5102, pp. 1745-1749, 1993.

[6] B. Wang, K. E. Ugen, V. Srikantan, et al., "Gene inoculation generates immune responses against human immunodeficiency virus type 1," Proceedings of the National Academy of Sciences of the United States of America, vol. 90, no. 9, pp. 4156-4160, 1993.

[7] E. Raz, D. A. Carson, S. E. Parker, et al., "Intradermal gene immunization: the possible role of DNA uptake in the induction of cellular immunity to viruses," Proceedings of the National Academy of Sciences of the United States of America, vol. 91, no. 20, pp. 9519-9523, 1994.

[8] J. J. Donnelly, J. B. Ulmer, J. W. Shiver, and M. A. Liu, "DNA vaccines," Annual Review of Immunology, vol. 15, pp. 617648, 1997.

[9] K. Haupt, M. Roggendorf, and K. Mann, "The potential of DNA vaccination against tumor-associated antigens for antitumor therapy," Experimental Biology and Medicine, vol. 227, no. 4, pp. 227-237, 2002.

[10] J. R. Yannelli and J. M. Wroblewski, "On the road to a tumor cell vaccine: 20 years of cellular immunotherapy," Vaccine, vol. 23, no. 1, pp. 97-113, 2004.

[11] A. J. George and F. K. Stevenson, "Prospects for the treatment of B cell tumors using idiotypic vaccination," International Reviews of Immunology, vol. 4, no. 4, pp. 271-310, 1989.

[12] P. Van der Bruggen, Y. Zhang, P. Chaux, et al., "Tumorspecific shared antigenic peptides recognized by human $\mathrm{T}$ cells," Immunological Reviews, vol. 188, pp. 51-64, 2002.

[13] F. K. Stevenson, J. Rice, and D. Zhu, "Tumor vaccines," Advances in Immunology, vol. 82, pp. 49-103, 2004.

[14] O. L. Caballero and Y.-T. Chen, "Cancer/testis (CT) antigens: potential targets for immunotherapy," Cancer Science, vol. 100, no. 11, pp. 2014-2021, 2009.

[15] R.-F. Wang and S. A. Rosenberg, "Human tumor antigens for cancer vaccine development," Immunological Reviews, vol. 170, pp. 85-100, 1999.

[16] M. L. Disis and M. A. Cheever, "HER-2/neu oncogenic protein: issues in vaccine development," Critical Reviews in Immunology, vol. 18, no. 1-2, pp. 37-45, 1998. 
[17] N. L. Berinstein, "Carcinoembryonic antigen as a target for therapeutic anticancer vaccines: a review," Journal of Clinical Oncology, vol. 20, no. 8, pp. 2197-2207, 2002.

[18] P. F. Robbins, M. El-Gamil, Y. Kawakami, and S. A. Rosenberg, "Recognition of tyrosinase by tumor-infiltrating lymphocytes from a patient responding to immunotherapy," Cancer Research, vol. 54, no. 12, pp. 3124-3126, 1994.

[19] Y. Kawakami, S. Eliyahu, C. H. Delgado, et al., "Cloning of the gene coding for a shared human melanoma antigen recognized by autologous T cells infiltrating into tumor," Proceedings of the National Academy of Sciences of the United States of America, vol. 91, no. 9, pp. 3515-3519, 1994.

[20] Y. Kawakami, S. Eliyahu, C. H. Delgado, et al., "Identification of a human melanoma antigen recognized by tumor- infiltrating lymphocytes associated with in vivo tumor rejection," Proceedings of the National Academy of Sciences of the United States of America, vol. 91, no. 14, pp. 6458-6462, 1994.

[21] C. Doehn, T. Bohmer, I. Kausch, M. Sommerauer, and D. Jocham, "Prostate cancer vaccines: current status and future potential," BioDrugs, vol. 22, no. 2, pp. 71-84, 2008.

[22] M. A. Cheever, J. P. Allison, A. S. Ferris, et al., "The prioritization of cancer antigens: a National Cancer Institute pilot project for the acceleration of translational research," Clinical Cancer Research, vol. 15, no. 17, pp. 5323-5337, 2009.

[23] R. G. Webster and H. L. Robinson, "DNA vaccines: a review of developments,” BioDrugs, vol. 8, no. 4, pp. 273-292, 1997.

[24] M. A. Liu and J. B. Ulmer, "Human clinical trials of plasmid DNA vaccines," Advances in Genetics, vol. 55, pp. 25-40, 2005.

[25] A. Porgador, K. R. Irvine, A. Iwasaki, B. H. Barber, N. P. Restifo, and R. N. Germain, "Predominant role for directly transfected dendritic cells in antigen presentation to $\mathrm{CD} 8^{+} \mathrm{T}$ cells after gene gun immunization," Journal of Experimental Medicine, vol. 188, no. 6, pp. 1075-1082, 1998.

[26] T.-M. Fu, J. B. Ulmer, M. J. Caulfield, et al., "Priming of cytotoxic T lymphocytes by DNA vaccines: requirement for professional antigen presenting cells and evidence for antigen transfer from myocytes," Molecular Medicine, vol. 3, no. 6, pp. 362-371, 1997.

[27] C. A. T. Torres, A. Iwasaki, B. H. Barber, and H. L. Robinson, "Differential dependence on target site tissue for gene gun and intramuscular DNA immunizations," Journal of Immunology, vol. 158, no. 10, pp. 4529-4532, 1997.

[28] M. Dupuis, K. Denis-Mize, C. Woo, et al., "Distribution of DNA vaccines determines their immunogenicity after intramuscular injection in mice," Journal of Immunology, vol. 165, no. 5, pp. 2850-2858, 2000.

[29] D. Haddad, J. Ramprakash, M. Sedegah, et al., "Plasmid vaccine expressing granulocyte-macrophage colony-stimulating factor attracts infiltrates including immature dendritic cells into injected muscles," Journal of Immunology, vol. 165, no. 7, pp. 3772-3781, 2000.

[30] M. A. Chattergoon, T. M. Robinson, J. D. Boyer, and D. B. Weiner, "Specific immune induction following DNA-based immunization through in vivo transfection and activation of macrophages/antigen-presenting cells," Journal of Immunology, vol. 160, no. 12, pp. 5707-5718, 1998.

[31] R. J. Anderson and J. Schneider, "Plasmid DNA and viral vector-based vaccines for the treatment of cancer," Vaccine, vol. 25, supplement 2, pp. B24-B34, 2007.

[32] S. Gurunathan, D. M. Klinman, and R. A. Seder, "DNA vaccines: immunology, application, and optimization," Annual Review of Immunology, vol. 18, pp. 927-974, 2000.

[33] C. G. Drake, E. Jaffee, and D. M. Pardoll, "Mechanisms of immune evasion by tumors," Advances in Immunology, vol. 90, pp. 51-81, 2006.
[34] B. Seliger, "Strategies of tumor immune evasion," BioDrugs, vol. 19, no. 6, pp. 347-354, 2005.

[35] D. B. Lowe, M. H. Shearer, C. A. Jumper, and R. C. Kennedy, "Towards progress on DNA vaccines for cancer," Cellular and Molecular Life Sciences, vol. 64, no. 18, pp. 2391-2403, 2007.

[36] P. Gregorevic, M. J. Blankinship, and J. S. Chamberlain, "Viral vectors for gene transfer to striated muscle," Current Opinion in Molecular Therapeutics, vol. 6, no. 5, pp. 491-498, 2004.

[37] S. Hacein-Bey-Abina, C. Von Kalle, M. Schmidt, et al., "LMO2-associated clonal T cell proliferation in two patients after gene therapy for SCID-X1," Science, vol. 302, no. 5644, pp. 415-419, 2003.

[38] V. M. Fazio, F. Ria, E. Franco, et al., "Immune response at birth, long-term immune memory and 2 years follow-up after in-utero anti-HBV DNA immunization," Gene Therapy, vol. 11, no. 6, pp. 544-551, 2004.

[39] M. Rinaldi, E. Signori, P. Rosati, et al., "Feasibilty of in utero DNA vaccination following naked gene transfer into pig fetal muscle: transgene expression, immunity and safety," Vaccine, vol. 24, no. 21, pp. 4586-4591, 2006.

[40] R. R. MacGregor, J. D. Boyer, K. E. Ugen, et al., "First human trial of a DNA-based vaccine for treatment of human immunodeficiency virus type 1 infection: safety and host response," Journal of Infectious Diseases, vol. 178, no. 1, pp. 92-100, 1998.

[41] M. Mincheff, S. Tchakarov, S. Zoubak, et al., "Naked DNA and adenoviral immunizations for immunotherapy of prostate cancer: a phase I/II clinical trial," European Urology, vol. 38, no. 2, pp. 208-217, 2000.

[42] T. P. Le, K. M. Coonan, R. C. Hedstrom, et al., "Safety, tolerability and humoral immune responses after intramuscular administration of a malaria DNA vaccine to healthy adult volunteers," Vaccine, vol. 18, no. 18, pp. 1893-1901, 2000.

[43] H. A. Smith, "Regulation and review of DNA vaccine products," Developments in Biologicals, vol. 104, pp. 57-62, 2000.

[44] Z. Cui, "DNA vaccine," Advances in Genetics, vol. 54, pp. 257289, 2005.

[45] J. Wolff, D. L. Lewis, H. Herweijer, J. Hegge, and J. Hagstrom, "Non-viral approaches for gene transfer," Acta Myologica, vol. 24, no. 3, pp. 202-208, 2005.

[46] S. Buchan, E. Grønevik, I. Mathiesen, C. A. King, F. K. Stevenson, and J. Rice, "Electroporation as a "prime/boost" strategy for naked DNA vaccination against a tumor antigen," Journal of Immunology, vol. 174, no. 10, pp. 6292-6298, 2005.

[47] J. Rice, C. H. Ottensmeier, and F. K. Stevenson, "DNA vaccines: precision tools for activating effective immunity against cancer," Nature Reviews Cancer, vol. 8, no. 2, pp. 108120, 2008.

[48] M. Rinaldi, D. Fioretti, S. Iurescia, et al., "Anti-tumor immunity induced by CDR3-based DNA vaccination in a murine B-cell lymphoma model," Biochemical and Biophysical Research Communications, vol. 370, no. 2, pp. 279-284, 2008.

[49] A.-K. Roos, F. Eriksson, J. A. Timmons, et al., "Skin electroporation: effects on transgene expression, DNA persistence and local tissue environment," PLOS ONE, vol. 4, no. 9, article e7226, 2009.

[50] A. Brave, D. Hallengard, L. Gudmundsdotter, et al., "Late administration of plasmid DNA by intradermal electroporation efficiently boosts DNA-primed T and B cell responses 
to carcinoembryonic antigen," Vaccine, vol. 27, no. 28, pp. 3692-3696, 2009.

[51] C. Trimble, C.-T. Lin, C.-F. Hung, et al., "Comparison of the $\mathrm{CD}^{+} \mathrm{T}$ cell responses and antitumor effects generated by DNA vaccine administered through gene gun, biojector, and syringe," Vaccine, vol. 21, no. 25-26, pp. 4036-4042, 2003.

[52] P.-J. Lou, W.-F. Cheng, Y.-C. Chung, C.-Y. Cheng, L.-H. Chiu, and T.-H. Young, "PMMA particle-mediated DNA vaccine for cervical cancer," Journal of Biomedical Materials Research, Part A, vol. 88, no. 4, pp. 849-857, 2009.

[53] S. G. L. Quaak, J. H. van den Berg, M. Toebes, et al., "GMP production of pDERMATT for vaccination against melanoma in a phase I clinical trial," European Journal of Pharmaceutics and Biopharmaceutics, vol. 70, no. 2, pp. 429438, 2008.

[54] R. C.-F. Chan, B. Gutierrez, T. E. Ichim, and F. Lin, "Enhancement of DNA cancer vaccine efficacy by combination with anti-angiogenesis in regression of established subcutaneous B16 melanoma," Oncology Reports, vol. 22, no. 5, pp. 11971203, 2009.

[55] N. Settelen, O. Roch, D. Bock, R. Rooke, S. Braun, and O. Meyer, "Controlled plasmid gene transfer to murine renal carcinoma by hexadecylphosphocholine," Journal of Controlled Release, vol. 94, no. 1, pp. 237-244, 2004.

[56] J. M. Timmerman, G. Singh, G. Hermanson, et al., "Immunogenicity of a plasmid DNA vaccine encoding chimeric idiotype in patients with B-cell lymphoma," Cancer Research, vol. 62, no. 20, pp. 5845-5852, 2002.

[57] S. A. Rosenberg, J. C. Yang, R. M. Sherry, et al., "Inability to immunize patients with metastatic melanoma using plasmid DNA encoding the gp100 melanoma-melanocyte antigen," Human Gene Therapy, vol. 14, no. 8, pp. 709-714, 2003.

[58] K. Todorova, I. Ignatova, S. Tchakarov, et al., "Humoral immune response in prostate cancer patients after immunization with gene-based vaccines that encode for a protein that is proteasomally degraded," Cancer Immunity, vol. 5, p. $1,2005$.

[59] A. M. Miller, V. Ozenci, R. Kiessling, and P. Pisa, "Immune monitoring in a phase 1 trial of a PSA DNA vaccine in patients with hormone-refractory prostate cancer," Journal of Immunotherapy, vol. 28, no. 4, pp. 389-395, 2005.

[60] W. S. Meng, L. H. Butterfield, A. Ribas, et al., " $\alpha$-fetoproteinspecific tumor immunity induced by plasmid primeadenovirus boost genetic vaccination," Cancer Research, vol. 61, no. 24, pp. 8782-8786, 2001.

[61] D. G. McNeel, E. J. Dunphy, J. G. Davies, et al., "Safety and immunological efficacy of a DNA vaccine encoding prostatic acid phosphatase in patients with stage D0 prostate cancer," Journal of Clinical Oncology, vol. 27, no. 25, pp. 4047-4054, 2009.

[62] M.-A. Perales, J. Yuan, S. Powel, et al., "Phase I/II study of GM-CSF DNA as an adjuvant for a multipeptide cancer vaccine in patients with advanced melanoma," Molecular Therapy, vol. 16, no. 12, pp. 2022-2029, 2008.

[63] A. Biragyn and L. W. Kwak, "Models for lymphoma," in Current Protocols in Immunology, chapter 20, p. unit 20.6, 2002.

[64] L. Low, A. Mander, K. McCann, et al., "DNA vaccination with electroporation induces increased antibody responses in patients with prostate cancer," Human Gene Therapy, vol. 20, no. 11, pp. 1269-1278, 2009.

[65] A. Mander, F. Chowdhury, L. Low, and C. H. Ottensmeier, "Fit for purpose? A case study: validation of immunological endpoint assays for the detection of cellular and humoral responses to anti-tumour DNA fusion vaccines," Cancer Immunology, Immunotherapy, vol. 58, no. 5, pp. 789-800, 2009.

[66] F. Takeshita, T. Tanaka, T. Matsuda, et al., "Toll-like receptor adaptor molecules enhance DNA-raised adaptive immune responses against influenza and tumors through activation of innate immunity," Journal of Virology, vol. 80, no. 13, pp. 6218-6224, 2006.

[67] C. L. Trimble, S. Peng, F. Kos, et al., "A phase I trial of a human papillomavirus DNA vaccine for HPV16+ cervical intraepithelial neoplasia 2/3," Clinical Cancer Research, vol. 15, no. 1, pp. 361-367, 2009.

[68] Y. Lu, K. Ouyang, J. Fang, et al., "Improved efficacy of DNA vaccination against prostate carcinoma by boosting with recombinant protein vaccine and by introduction of a novel adjuvant epitope," Vaccine, vol. 27, no. 39, pp. 5411-5418, 2009.

[69] C. L. Smith, P. R. Dunbar, F. Mirza, et al., "Recombinant modified vaccinia Ankara primes functionally activated CTL specific for a melanoma tumor antigen epitope in melanoma patients with a high risk of disease recurrence," International Journal of Cancer, vol. 113, no. 2, pp. 259-266, 2005.

[70] D. L. Montgomery, J. J. Donnelly, J. W. Shiver, M. A. Liu, and J. B. Ulmer, "Protein expression in vivo by injection of polynucleotides," Current Opinion in Biotechnology, vol. 5, no. 5, pp. 505-510, 1994.

[71] D. A. Dean, D. D. Strong, and W. E. Zimmer, "Nuclear entry of nonviral vectors," Gene Therapy, vol. 12, no. 11, pp. 881890, 2005.

[72] B. Weide, C. Garbe, H.-G. Rammensee, and S. Pascolo, "Plasmid DNA- and messenger RNA-based anti-cancer vaccination," Immunology Letters, vol. 115, no. 1, pp. 33-42, 2008.

[73] S. S. Neelapu and L. W. Kwak, "Vaccine therapy for B-cell lymphomas: next-generation strategies," Hematology, vol. 2007, no. 1, pp. 243-249, 2007.

[74] K. Hoebe, Z. Jiang, K. Tabeta, et al., "Genetic analysis of innate immunity," Advances in Immunology, vol. 91, pp. 175226, 2006.

[75] D. Tudor, C. Dubuquoy, V. Gaboriau, F. Lefèvre, B. Charley, and S. Riffault, "TLR9 pathway is involved in adjuvant effects of plasmid DNA-based vaccines," Vaccine, vol. 23, no. 10, pp. 1258-1264, 2005.

[76] S. Saha, F. Takeshita, T. Matsuda, et al., "Blocking of the TLR5 activation domain hampers protective potential of flagellin DNA vaccine," Journal of Immunology, vol. 179, no. 2, pp. 1147-1154, 2007.

[77] D. J. Morgan, H. T. C. Kreuwel, and L. A. Sherman, "Antigen concentration and precursor frequency determine the rate of $\mathrm{CD}^{+} \mathrm{T}$ cell tolerance to peripherally expressed antigens," Journal of Immunology, vol. 163, no. 2, pp. 723-727, 1999.

[78] J. K. Sandberg, L. Franksson, J. Sandberg, et al., "T cell tolerance based on avidity thresholds rather than complete deletion allows maintenance of maximal repertoire diversity," Journal of Immunology, vol. 165, no. 1, pp. 25-33, 2000.

[79] J. A. Berzofsky, "Epitope selection and design of synthetic vaccines. Molecular approaches to enhancing immunogenicity and cross-reactivity of engineered vaccines," Annals of the New York Academy of Sciences, vol. 690, pp. 256-264, 1993.

[80] H.-G. Rammensee, T. Friede, and S. Stevanovic, "MHC ligands and peptide motifs: first listing," Immunogenetics, vol. 41, no. 4, pp. 178-228, 1995.

[81] J. Ruppert, J. Sidney, E. Celis, R. T. Kubo, H. M. Grey, and A. Sette, "Prominent role of secondary anchor residues in 
peptide binding to HLA-A2.1 molecules," Cell, vol. 74, no. 5, pp. 929-937, 1993.

[82] H. Mok, S. Lee, D. W. Wright, and J. E. Crowe Jr., "Enhancement of the $\mathrm{CD} 8^{+} \mathrm{T}$ cell response to a subdominant epitope of respiratory syncytial virus by deletion of an immunodominant epitope," Vaccine, vol. 26, no. 37, pp. 4775-4782, 2008.

[83] J. A. Berzofsky, J. D. Ahlers, and I. M. Belyakov, "Strategies for designing and optimizing new generation vaccines," Nature Reviews Immunology, vol. 1, no. 3, pp. 209-219, 2001.

[84] W. W. Leitner, E. S. Bergmann-Leitner, L. N. Hwang, and N. P. Restifo, "Type I Interferons are essential for the efficacy of replicase-based DNA vaccines," Vaccine, vol. 24, no. 24, pp. 5110-5118, 2006.

[85] J. A. Leifert, M. P. Rodriguez-Carreno, F. Rodriguez, and J. L. Whitton, "Targeting plasmid-encoded proteins to the antigen presentation pathways," Immunological Reviews, vol. 199, pp. 40-53, 2004.

[86] E. M. Janssen, E. E. Lemmens, T. Wolfe, U. Christen, M. G. Von Herrath, and S. P. Schoenberger, "CD4 ${ }^{+} \mathrm{T}$ cells are required for secondary expansion and memory in $\mathrm{CD}^{+} \mathrm{T}$ lymphocytes," Nature, vol. 421, no. 6925, pp. 852-856, 2003.

[87] F. K. Stevenson, J. Rice, C. H. Ottensmeier, S. M. Thirdborough, and D. Zhu, "DNA fusion gene vaccines against cancer: from the laboratory to the clinic," Immunological Reviews, vol. 199, pp. 156-180, 2004.

[88] F. K. Stevenson, C. H. Ottensmeier, P. Johnson, et al., "DNA vaccines to attack cancer," Proceedings of the National Academy of Sciences of the United States of America, vol. 101, supplement 2, pp. 14646-14652, 2004.

[89] R. Wang, D. L. Doolan, T. P. Le, et al., "Induction of antigenspecific cytotoxic $\mathrm{T}$ lymphocytes in humans by a malaria DNA vaccine," Science, vol. 282, no. 5388, pp. 476-480, 1998.

[90] S. Calarota, G. Bratt, S. Nordlund, et al., "Cellular cytotoxic response induced by DNA vaccination in HIV-1-infected patients," Lancet, vol. 351, no. 9112, pp. 1320-1325, 1998.

[91] B. S. Graham, R. A. Koup, M. Roederer, et al., "Phase 1 safety and immunogenicity evaluation of a multiclade HIV-1 DNA candidate vaccine," Journal of Infectious Diseases, vol. 194, no. 12, pp. 1650-1660, 2006.

[92] J. R. Greenland and N. L. Letvin, "Chemical adjuvants for plasmid DNA vaccines,” Vaccine, vol. 25 , no. 19, pp. 37313741, 2007.

[93] C. Dell'Agnola and A. Biragyn, "Clinical utilization of chemokines to combat cancer: the double-edged sword," Expert Review of Vaccines, vol. 6, no. 2, pp. 267-283, 2007.

[94] M. Rinaldi, F. Ria, P. Parrella, et al., "Antibodies elicited by naked DNA vaccination against the complementarydetermining region 3 hypervariable region of immunoglobulin heavy chain idiotypic determinants of Blymphoproliferative disorders specifically react with patients' tumor cells," Cancer Research, vol. 61, no. 4, pp. 1555-1562, 2001.

[95] S. A. Calarota and D. B. Weiner, "Enhancement of human immunodeficiency virus type 1-DNA vaccine potency through incorporation of T-helper 1 molecular adjuvants," Immunological Reviews, vol. 199, pp. 84-99, 2004.

[96] D. Zhu and F. K. Stevenson, "DNA gene fusion vaccines against cancer," Current Opinion in Molecular Therapeutics, vol. 4, no. 1, pp. 41-48, 2002.

[97] F. K. Stevenson and J. Rice, "Optimizing cancer immunotherapy trials: back to basics," European Journal of Immunology, vol. 36, no. 5, pp. 1070-1073, 2006.
[98] J. A. Keene and J. Forman, "Helper activity is required for the in vivo generation of cytotoxic T lymphocytes," Journal of Experimental Medicine, vol. 155, no. 3, pp. 768-782, 1982.

[99] M. G. Von Herrath, M. Yokoyama, J. Dockter, M. B. A. Oldstone, and J. L. Whitton, "CD4-deficient mice have reduced levels of memory cytotoxic $\mathrm{T}$ lymphocytes after immunization and show diminished resistance to subsequent virus challenge," Journal of Virology, vol. 70, no. 2, pp. 10721079, 1996.

[100] L. Elia, C. Mennuni, M. Storto, et al., "Genetic vaccines against Ep-CAM break tolerance to self in a limited subset of subjects: initial identification of predictive biomarkers," European Journal of Immunology, vol. 36, no. 5, pp. 13371349, 2006.

[101] S. Lu, S. Wang, and J. M. Grimes-Serrano, "Current progress of DNA vaccine studies in humans," Expert Review of Vaccines, vol. 7, no. 2, pp. 175-191, 2008.

[102] A. T. Stopeck, E. M. Hersh, E. T. Akporiaye, et al., "Phase I study of direct gene transfer of an allogeneic histocompatibility antigen, HLA-B7, in patients with metastatic melanoma," Journal of Clinical Oncology, vol. 15, no. 1, pp. 341-349, 1997.

[103] R. J. Drape, M. D. Macklin, L. J. Barr, S. Jones, J. R. Haynes, and H. J. Dean, "Epidermal DNA vaccine for influenza is immunogenic in humans," Vaccine, vol. 24, no. 21, pp. 44754481, 2006.

[104] M. A. Egan, S. Megati, V. Roopchand, et al., "Rational design of a plasmid DNA vaccine capable of eliciting cellmediated immune responses to multiple HIV antigens in mice," Vaccine, vol. 24, no. 21, pp. 4510-4523, 2006.

[105] A. Luckay, M. K. Sidhu, R. Kjeken, et al., "Effect of plasmid DNA vaccine design and in vivo electroporation on the resulting vaccine-specific immune responses in rhesus macaques," Journal of Virology, vol. 81, no. 10, pp. 5257-5269, 2007.

[106] G. Ahlen, J. Soderholm, T. Tjelle, et al., "In vivo electroporation enhances the immunogenicity of hepatitis $\mathrm{C}$ virus nonstructural 3/4A DNA by increased local DNA uptake, protein expression, inflammation, and infiltration of $\mathrm{CD}^{+} \mathrm{T}$ cells," Journal of Immunology, vol. 179, no. 7, pp. 4741-4753, 2007.

[107] M. P. Murtaugh and D. L. Foss, "Inflammatory cytokines and antigen presenting cell activation," Veterinary Immunology and Immunopathology, vol. 87, no. 3-4, pp. 109-121, 2002.

[108] J. Liu, R. Kjeken, I. Mathiesen, and D. H. Barouch, "Recruitment of antigen-presenting cells to the site of inoculation and augmentation of human immunodeficiency virus type 1 DNA vaccine immunogenicity by in vivo electroporation," Journal of Virology, vol. 82, no. 11, pp. 5643-5649, 2008.

[109] A. D. Bins, A. Jorritsma, M. C. Wolkers, et al., "A rapid and potent DNA vaccination strategy defined by in vivo monitoring of antigen expression," Nature Medicine, vol. 11, no. 8, pp. 899-904, 2005.

[110] A. D. Kelleher, R. L. Puls, M. Bebbington, et al., "A randomized, placebo-controlled phase I trial of DNA prime, recombinant fowlpox virus boost prophylactic vaccine for HIV-1," AIDS, vol. 20, no. 2, pp. 294-297, 2006.

[111] D. P. Webster, S. Dunachie, S. McConkey, et al., "Safety of recombinant fowlpox strain FP9 and modified vaccinia virus Ankara vaccines against liver-stage P. falciparum malaria in non-immune volunteers," Vaccine, vol. 24, no. 15, pp. 30263034, 2006.

[112] M. A. Egan, S. Y. Chong, S. Megati, et al., "Priming with plasmid DNAs expressing interleukin-12 and simian immunodeficiency virus gag enhances the immunogenicity and 
efficacy of an experimental AIDS vaccine based on recombinant vesicular stomatitis virus," AIDS Research and Human Retroviruses, vol. 21, no. 7, pp. 629-643, 2005.

[113] R. Wang, J. Epstein, Y. Charoenvit, et al., "Induction in humans of $\mathrm{CD}^{+}$and $\mathrm{CD}^{+} \mathrm{T}$ cell and antibody responses by sequential immunization with malaria DNA and recombinant protein," Journal of Immunology, vol. 172, no. 9, pp. 5561-5569, 2004.

[114] S. Wang, J. S. Kennedy, K. West, et al., "Cross-subtype antibody and cellular immune responses induced by a polyvalent DNA prime-protein boost HIV-1 vaccine in healthy human volunteers," Vaccine, vol. 26, no. 8, pp. 1098-1110, 2008.

[115] J. Schneider, S. C. Gilbert, C. M. Hannan, et al., "Induction of $\mathrm{CD}^{+} \mathrm{T}$ cells using heterologous prime-boost immunisation strategies," Immunological Reviews, vol. 170, pp. 29-38, 1999.

[116] J. Schneider, S. C. Gilbert, T. J. Blanchard, et al., "Enhanced immunogenicity for $\mathrm{CD}^{+} \mathrm{T}$ cell induction and complete protective efficacy of malaria DNA vaccination by boosting with modified vaccinia virus Ankara," Nature Medicine, vol. 4, no. 4, pp. 397-402, 1998.

[117] M. J. Estcourt, A. J. Ramsay, A. Brooks, S. A. Thomson, C. J. Medveckzy, and I. A. Ramshaw, "Prime-boost immunization generates a high frequency, high-avidity $\mathrm{CD}^{+}$cytotoxic T lymphocyte population," International Immunology, vol. 14, no. 1, pp. 31-37, 2002.

[118] P. Degano, J. Schneider, C. M. Hannan, S. C. Gilbert, and A. V. S. Hill, "Gene gun intradermal DNA immunization followed by boosting with modified vaccinia virus Ankara: enhanced $\mathrm{CD}^{+} \mathrm{T}$ cell immunogenicity and protective efficacy in the influenza and malaria models," Vaccine, vol. 18, no. 7-8, pp. 623-632, 1999.

[119] A. Sica and V. Bronte, "Altered macrophage differentiation and immune dysfunction in tumor development," Journal of Clinical Investigation, vol. 117, no. 5, pp. 1155-1166, 2007.

[120] T. J. Curiel, "Tregs and rethinking cancer immunotherapy," Journal of Clinical Investigation, vol. 117, no. 5, pp. 11671174, 2007.

[121] L. W. Collison, C. J. Workman, T. T. Kuo, et al., "The inhibitory cytokine IL-35 contributes to regulatory T-cell function," Nature, vol. 450, no. 7169, pp. 566-569, 2007.

[122] D. H. Munn and A. L. Mellor, "Indoleamine 2,3-dioxygenase and tumor-induced tolerance," Journal of Clinical Investigation, vol. 117, no. 5, pp. 1147-1154, 2007.

[123] L. A. Emens, R. T. Reilly, and E. M. Jaffee, "Breast cancer vaccines: maximizing cancer treatment by tapping into host immunity," Endocrine-Related Cancer, vol. 12, no. 1, pp. 117, 2005.

[124] W. Zou, "Immunosuppressive networks in the tumour environment and their therapeutic relevance," Nature Reviews Cancer, vol. 5, no. 4, pp. 263-274, 2005.

[125] R. Xiang, Y. Luo, A. G. Niethammer, and R. A. Reisfeld, "Oral DNA vaccines target the tumor vasculature and microenvironment and suppress tumor growth and metastasis," Immunological Reviews, vol. 222, no. 1, pp. 117-128, 2008.

[126] A. G. Niethammer, R. Xiang, J. C. Becker, et al., "A DNA vaccine against VEGF receptor 2 prevents effective angiogenesis and inhibits tumor growth," Nature Medicine, vol. 8, no. 12, pp. 1369-1375, 2002.

[127] C. D. Kaplan, J. A. Kruger, H. Zhou, Y. Luo, R. Xiang, and R. A. Reisfeld, "A novel DNA vaccine encoding PDGFR $\beta$ suppresses growth and dissemination of murine colon, lung and breast carcinoma," Vaccine, vol. 24, no. 47-48, pp. 69947002, 2006.
[128] S. M. Sumida, P. F. McKay, D. M. Truitt, et al., "Recruitment and expansion of dendritic cells in vivo potentiate the immunogenicity of plasmid DNA vaccines," Journal of Clinical Investigation, vol. 114, no. 9, pp. 1334-1342, 2004.

[129] J. Steitz, J. Bruck, J. Lenz, J. Knop, and T. Tuting, "Depletion of $\mathrm{CD} 25^{+} \mathrm{CD} 4^{+} \mathrm{T}$ cells and treatment with tyrosinase-related protein 2-transduced dendritic cells enhance the interferon $\alpha$-induced, $\mathrm{CD}^{+}{ }^{+}$T-cell-dependent immune defense of B16 melanoma," Cancer Research, vol. 61, no. 24, pp. 8643-8646, 2001.

[130] R. P. M. Sutmuller, L. M. Van Duivenvoorde, A. Van Elsas, et al., "Synergism of cytotoxic T lymphocyte-associated antigen 4 blockade and depletion of $\mathrm{CD} 25^{+}$regulatory T cells in antitumor therapy reveals alternative pathways for suppression of autoreactive cytotoxic T lymphocyte responses," Journal of Experimental Medicine, vol. 194, no. 6, pp. 823-832, 2001.

[131] O. M. Grauer, S. Nierkens, E. Bennink, et al., "CD4 ${ }^{+}$FoxP3 ${ }^{+}$ regulatory $\mathrm{T}$ cells gradually accumulate in gliomas during tumor growth and efficiently suppress antiglionia immune responses in vivo," International Journal of Cancer, vol. 121, no. 1, pp. 95-105, 2007.

[132] A. Chen, S. Liu, D. Park, Y. Kang, and G. Zheng, "Depleting intratumoral $\mathrm{CD} 4{ }^{+} \mathrm{CD} 25^{+}$regulatory $\mathrm{T}$ cells via FasL protein transfer enhances the therapeutic efficacy of adoptive $\mathrm{T}$ cell transfer," Cancer Research, vol. 67, no. 3, pp. 1291-1298, 2007.

[133] K. L. Knutson, Y. Dang, H. Lu, et al., "IL-2 immunotoxin therapy modulates tumor-associated regulatory $\mathrm{T}$ cells and leads to lasting immune-mediated rejection of breast cancers in neu-transgenic mice," Journal of Immunology, vol. 177, no. 1, pp. 84-91, 2006.

[134] J. Dannull, Z. Su, D. Rizzieri, et al., "Enhancement of vaccine-mediated antitumor immunity in cancer patients after depletion of regulatory T cells," Journal of Clinical Investigation, vol. 115, no. 12, pp. 3623-3633, 2005.

[135] K. Mahnke, K. Schonfeld, S. Fondel, et al., "Depletion of $\mathrm{CD} 4^{+} \mathrm{CD} 25^{+}$human regulatory $\mathrm{T}$ cells in vivo: kinetics of Treg depletion and alterations in immune functions in vivo and in vitro," International Journal of Cancer, vol. 120, no. 12, pp. 2723-2733, 2007.

[136] T. J. Curiel, G. Coukos, L. Zou, et al., "Specific recruitment of regulatory $\mathrm{T}$ cells in ovarian carcinoma fosters immune privilege and predicts reduced survival," Nature Medicine, vol. 10, no. 9, pp. 942-949, 2004.

[137] B. Li, A. S. Lalani, T. C. Harding, et al., "Vascular endothelial growth factor blockade reduces intratumoral regulatory $\mathrm{T}$ cells and enhances the efficacy of a GM-CSF-secreting cancer immunotherapy," Clinical Cancer Research, vol. 12, no. 22, pp. 6808-6816, 2006.

[138] J. Ruter, B. G. Barnett, I. Kryczek, et al., "Altering regulatory T cell function in cancer immunotherapy: a novel means to boost the efficacy of cancer vaccines," Frontiers in Bioscience, vol. 14, pp. 1761-1770, 2009.

[139] B. J. Ledwith, S. Manam, P. J. Troilo, et al., "Plasmid DNA vaccines: investigation of integration into host cellular DNA following intramuscular injection in mice," Intervirology, vol. 43, no. 4-6, pp. 258-272, 2000.

[140] R. L. Sheets, J. Stein, T. S. Manetz, et al., "Biodistribution of DNA plasmid vaccines against HIV-1, Ebola, Severe Acute Respiratory Syndrome, or West Nile virus is similar, without integration, despite differing plasmid backbones or gene inserts," Toxicological Sciences, vol. 91, no. 2, pp. 610-619, 2006. 
[141] M. L. Bagarazzi, J. D. Boyer, M. A. Javadian, et al., "Safety and immunogenicity of intramuscular and intravaginal delivery of HIV-1 DNA constructs to infant chimpanzees," Journal of Medical Primatology, vol. 26, no. 1-2, pp. 27-33, 1997.

[142] R. E. Hawkins, D. Zhu, M. Ovecka, et al., "Idiotypic vaccination against human B-cell lymphoma. Rescue of variable region gene sequences from biopsy material for assembly as single-chain Fv personal vaccines," Blood, vol. 83, no. 11, pp. 3279-3288, 1994.

[143] L. E. Johnson, T. P. Frye, A. R. Arnot, et al., "Safety and immunological efficacy of a prostate cancer plasmid DNA vaccine encoding prostatic acid phosphatase (PAP)," Vaccine, vol. 24, no. 3, pp. 293-303, 2006.

[144] S. T. Tagawa, P. Lee, J. Snively, et al., "Phase I study of intranodal delivery of a plasmid DNA vaccine for patients with Stage IV melanoma," Cancer, vol. 98, no. 1, pp. 144-154, 2003.

[145] J. Weber, W. Boswell, J. Smith, et al., "Phase 1 trial of intranodal injection of a melan-A/MART-1 DNA plasmid vaccine in patients with stage IV melanoma," Journal of Immunotherapy, vol. 31, no. 2, pp. 215-223, 2008.

[146] D. Kim, R. Gambhira, B. Karanam, et al., "Generation and characterization of a preventive and therapeutic HPV DNA vaccine," Vaccine, vol. 26, no. 3, pp. 351-360, 2008.

[147] M. Rinaldi, S. Iurescia, D. Fioretti, A. Ponzetto, and G. Carloni, "Strategies for successful vaccination against hepatocellular carcinoma," International Journal of Immunopathology and Pharmacology, vol. 22, no. 2, pp. 269-277, 2009.

[148] M. L. Disis, K. Schiffman, K. Guthrie, et al., "Effect of dose on immune response in patients vaccinated with an HER2/neu intracellular domain protein-based vaccine," Journal of Clinical Oncology, vol. 22, no. 10, pp. 1916-1925, 2004.

[149] S. Coleman, A. Clayton, M. D. Mason, B. Jasani, M. Adams, and Z. Tabi, "Recovery of $\mathrm{CD}^{+}{ }^{+}$T-cell function during systemic chemotherapy in advanced ovarian cancer," Cancer Research, vol. 65, no. 15, pp. 7000-7006, 2005. 


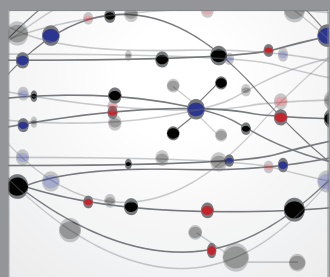

The Scientific World Journal
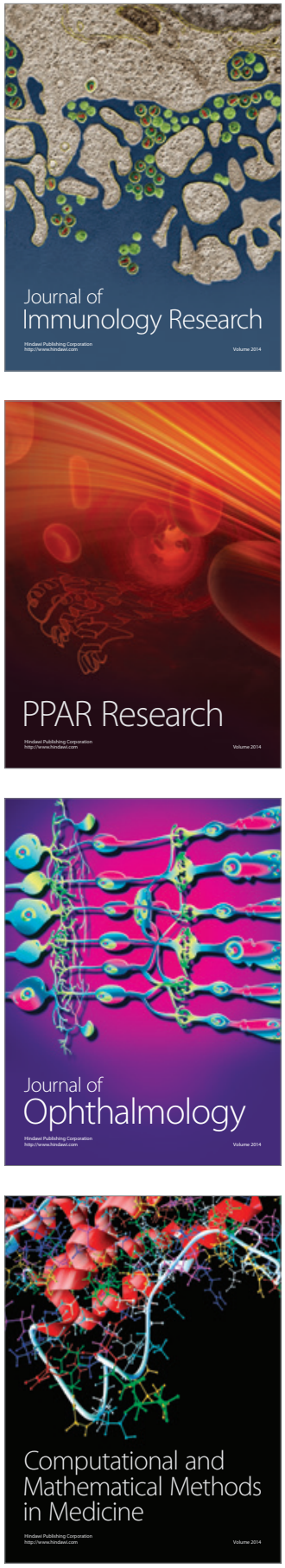

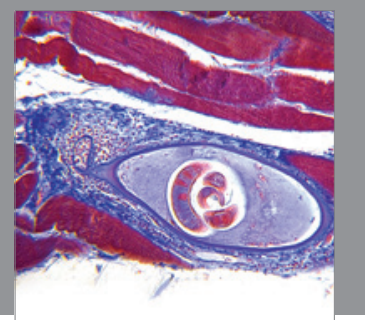

Gastroenterology

Research and Practice
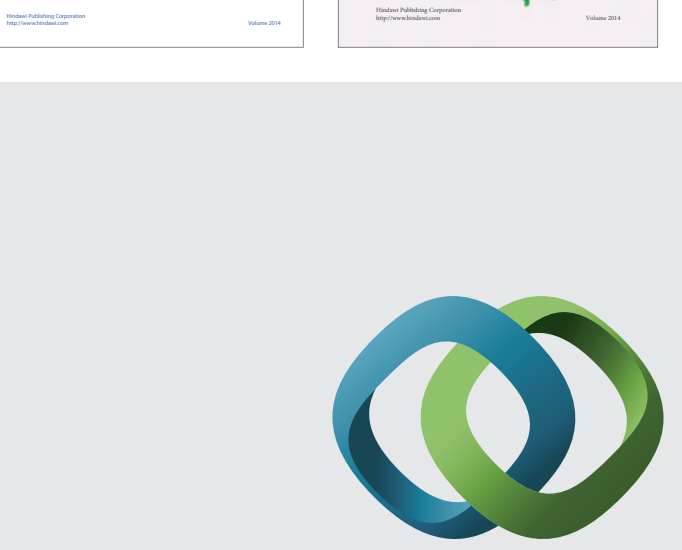

\section{Hindawi}

Submit your manuscripts at

http://www.hindawi.com
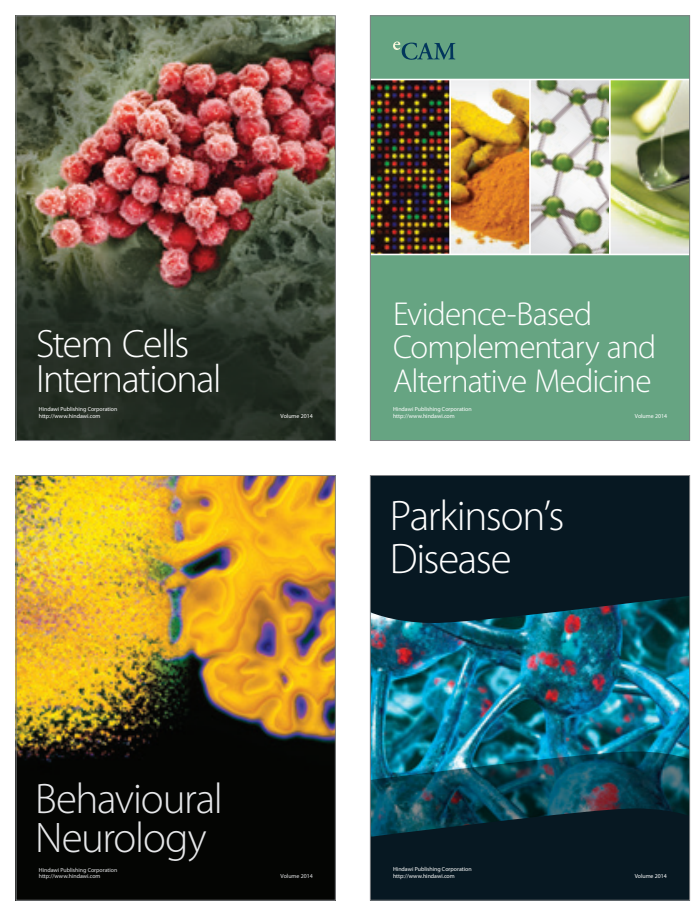

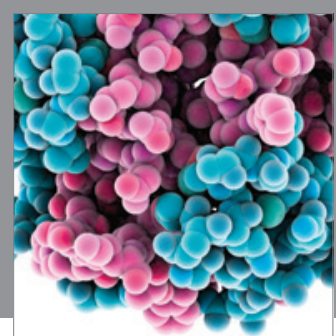

Journal of
Diabetes Research

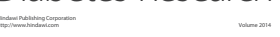

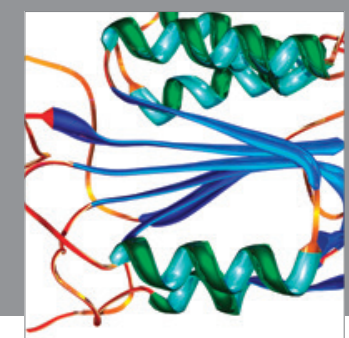

Disease Markers
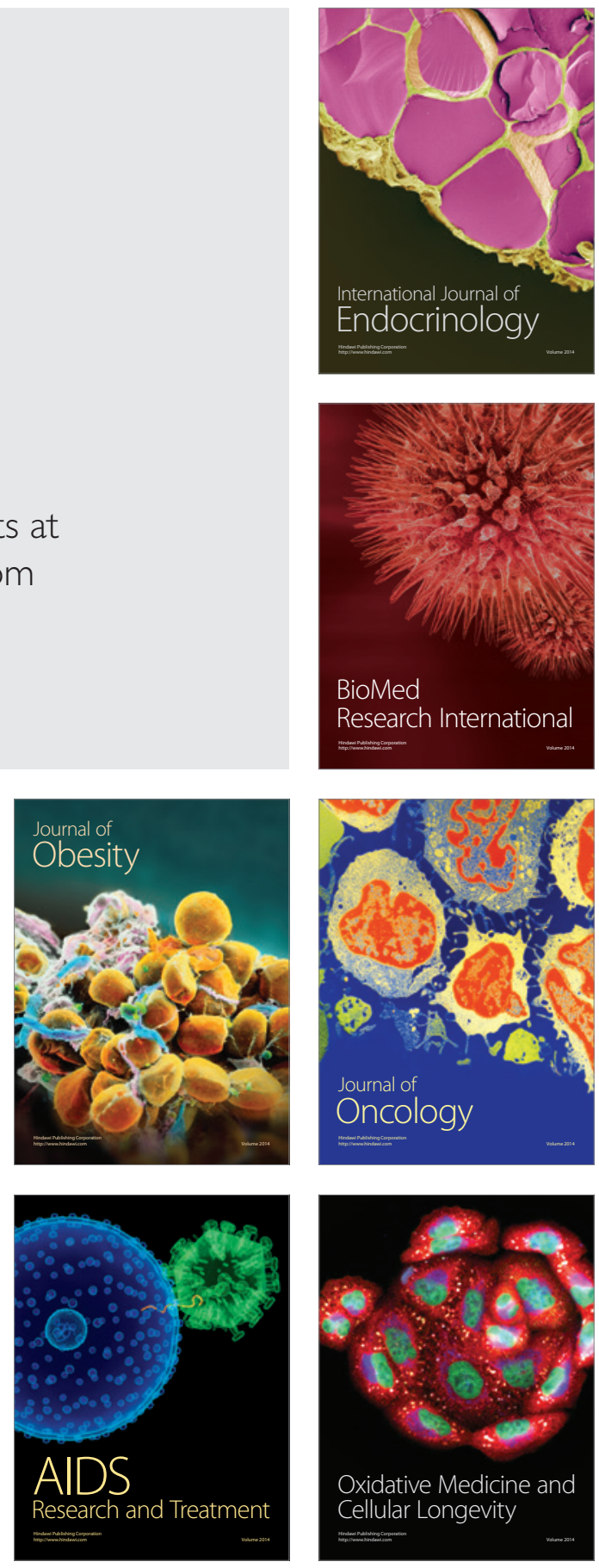